\title{
The Diffusion of Collective Violence: Infectiousness, Susceptibility, and Mass Media Networks ${ }^{1}$
}

\author{
Daniel J. Myers \\ University of Notre Dame
}

\begin{abstract}
Using recent advances in event history diffusion modeling, this article reexamines the diffusion of racial rioting in the United States from 1964-71, uncovering several important aspects of diffusion not evident from prior analyses. First, riots are not independent events, and modeling them as such results in an inadequate understanding of the violence wave. Second, cities not only have differential intrinsic propensities to riot, but also different levels of responsiveness and resistance to diffusion from other riots. Third, implied networks related to mass media distribution provide the pathway along which riot diffusion is transmitted. These combined results underscore the necessity of conceptualizing riots as a series of interdependent events, which diffuse in different patterns depending on the characteristics of the riot and the city in which it occurs, and they further accentuate the paramount importance of the mass media in creating and sustaining collective violence and protest waves.
\end{abstract}

\section{INTRODUCTION}

On August 11, 1965, a riot broke out in Los Angeles in and around an area called Watts. This riot was to be one of the most important of the era, not only because of its intensity, but also because it seemed to inaugurate the wave of urban racial riots that characterized America in the 1960s (McAdam 1983). Watts was by no means America's first race riot, but its process and outcomes heralded a new protest tactic that would

\footnotetext{
${ }^{1}$ This research was supported by grant SBR 96-01409 from the National Science Foundation. I thank Pamela Oliver, Gerald Marwell, Alberto Palloni, Lawrence Wu, Meg Varley, and Alexandra Corning for comments on earlier drafts and Gregg Carter for supplying his riot data. Send correspondence to Daniel J. Myers, Department of Sociology, 810 Flanner Hall, Notre Dame, Indiana 46556. E-mail: Myers.33@nd.edu

(C) 2000 by the University of Chicago. All rights reserved. 0002-9602/2000/10601-0005\$02.50
} 
American Journal of Sociology

supplant the nonviolent actions of the Civil Rights movement as the dominant expression of race relations in the United States

Because the problems thought to have driven the Watts riot could not be solved quickly, scholars, politicians, activists, and citizens wondered whether Watts was the culmination of urban unrest or a harbinger of things to come. In many cities, ghetto conditions were deplorable, relationships between black communities and police departments were tense, and militant rhetoric supporting more extreme action was on the rise. In some instances, explicit threats of Watts-style action fueled the public's fears (Crump 1966).

If further violence was to be prevented, either by repressive force or by addressing the grievances of those who might riot, governments and activists needed to mobilize money, equipment, and people. But how could they know where to target these efforts? Unfortunately, predicting riots turned out to be a notoriously difficult task, and even retrospective analyses have had difficulty explaining rioting using the social and economic conditions presumed to be at issue (Spilerman 1970, 1971, 1976; Carter 1983, 1986; Jiobu 1971; Lieske 1978; see McPhail [1994] for an overview). After examining a multitude of city-level structural and economic variables, Spilerman $(1970,1976)$ concluded that the only useful predictors of rioting were the black population of a city and whether the city was located in the South. Spilerman recognized that ghetto conditions were poor everywhere and that blacks had generally accepted rioting to be a reasonable protest mechanism. He reasoned, therefore, that rioting would have to be a near random function of the number of blacks available to participate in a riot.

Another potential explanation for the "where" and "when" of riots did exist, however, and although this explanation has been mentioned in a number of reports and studies, empirical examination remains underdeveloped. Some observers believed that riots were in some sense "contagious" to one another. The Kerner commission, in studying the riots of the summer of 1967 , noted that many riots could be configured into geographic and temporal clusters in which later riots appeared to flow from earlier ones (National Advisory Commission on Civil Disorders 1968). In particular, there were marked clusters of riots related to the two most intense outbreaks-Detroit, Michigan, and Newark, New Jersey-which provided the provocative hypothesis of riot contagion. Some analyses of the riots that followed, particularly Spilerman's (1970), attempted to test this hypothesis but failed to find any significant effects. Unfortunately, the analytic techniques used to examine the hypothesis were ill-suited to providing convincing evidence one way or another, and the issue was effectively abandoned.

In this article, I reexamine the riot wave for evidence of diffusion effects. 


\section{Collective Violence}

By using Strang and Tuma's (1993) event history approach to diffusion modeling, I uncover several important diffusion effects within the riot wave. First, I show that riot infectiousness is controlled by the severity of the riot, suggesting the importance of media attention to the diffusion process. Second, I show that cities differ in their responsiveness to contagious influence from other cities and that these differences are tied to the size of the black population in each city. Third, I examine television broadcast patterns, which create information networks among cities, and I demonstrate that these networks were critically important in transmitting the propensity to riot from one location to another. These combined results underscore the necessity of understanding riots as a series of interdependent events and further emphasize the paramount importance of the mass media in creating and sustaining collective violence and protest waves.

\section{RIOT CONTAGION}

Beyond the technical difficulties of testing for contagion or diffusion processes, inter-actor influence hypotheses have been neglected in the study of collective action for another reason. Early crowd theorists (e.g. LeBon [1895] 1960; Freud 1921) asserted that individuals in a crowd could be "infected," or swept away by the collective body as a kind of unconscious, primitive craze passed from individual to individual. Since then, such views of crowds have been thoroughly debunked (see McPhail [1991] for a complete history of crowd psychology). Nevertheless, the unfortunate history of contagion in theories of collectives has caused an ongoing reluctance to incorporate diffusion notions into explanations for collective behavior for fear of conjuring LeBonian ghosts.

It is not necessary, however, to follow LeBon's view of the crowd when invoking contagion processes. Modern variants of "contagion" notions recognize that diffusion is a rational form of inter-actor influence in which potential actors observe and evaluate the outcomes of others' behaviors and then make a decision for themselves about whether or not to adopt the behavior (Oberschall 1980, 1989). This variant of contagion has long been used in studies of collective behaviors including rioting (Hobsbawn and Rudé 1968; Charlesworth 1979; Bohstedt 1994; Bohstedt and Williams 1988; Olzak and Shanahan 1996; Myers 1997b), protest tactics (McAdam 1983; Oberschall 1989), hijacking, coups, other collective violence (Pitcher, Hamblin, and Miller 1978; Hamblin, Jacobsen, and Miller 1973), and even fads (Aguirre, Quarantelli, and Mendoza 1988).

Formally, contagious influence is part of a collective behavior process when one collective actor engages in an act of protest or violence and their behavior changes the probability of future similar acts (Oberschall 
American Journal of Sociology

1980, 1989; Spilerman 1970; Pitcher, Hamblin, and Miller 1978; Myers 1997b; Shanahan and Olzak 1998; Aguirre, Quarantelli, and Mendoza 1988). How and why would this occur with riots in general and the racial riots of the 1960s in particular? Several relevant perspectives have emerged that may be categorized according to whether the contagion effects are assumed to be temporary or part of a long-term trend.

\section{Long-Term Contributions to Riot Waves}

When examining how a riot contributes to a long-term trend of collective violence, the most obvious engine driving a diffusion process is that some kind of positive reinforcement results from rioting (Spilerman 1970; Sears and Tomlinson 1968). Whether the gains are real, promised, or illusory, if potential rioters believe that prior violence led to gains by the rioters and other blacks, then they have increased impetus to riot themselves (Oliver 1989). Survey research conducted following major riots in the 1960s firmly established that this perspective was held by many blacks (Feagin and Hahn 1973). Even in neighborhoods destroyed by a riot, black residents believed that the riots were a positive influence and that they would ultimately improve the lot of inner-city blacks (Fogelson 1969; Bobo 1988; Marx 1967). The opinions of blacks were bolstered by the increased attention focused on ghetto conditions following major riots (e.g., Governor's Commission on the Los Angeles Riots 1966), and in some cases, this attention was accompanied by concrete action on the part of city and federal governments intended to address inner-city problems (Crump 1965; Button 1978; Issac and Kelly 1981).

The positive effects of rioting for blacks also took a more personal tone. When surveyed, the majority of blacks in the Watts area reported that they felt increased pride as blacks as a result of the riot (Fogelson 1969). These positive, personal reactions to rioting are evinced even more clearly in testimony given before the McCone commission (Hacker and Harmetz 1969): "It felt good all over." "We were whole people, not just servants." "It was the metamorphosis of the Negroes of southeastern Los Angeles from victims-historical objects—to masters." "I saw children respect their fathers for the first time." "Violence is an alternative to despair. Through violence yon can rid yourself of a torturing feeling of helplessness and nothingness." Blacks' experiences with rioting led to a more positive view of collective violence as a strategy for improving conditions and as an effective method of personal involvement in an important cause. It is no wonder then that outbreaks like Watts accelerated the riot wave.

Perhaps most important, riots like Watts provided a model for a new kind of protest behavior. The rioters in Watts were "setting an example, starting a pattern" (Hacker and Harmetz 1969). This model would be 


\section{Collective Violence}

publicized nationally, thanks to dramatic, unprecedented coverage captured by Los Angeles's KTLA helicopter cameras and replayed nationally by the network news. Through rioting, urban blacks across the nation expressed their growing frustration with nonviolent tactics (Tomlinson 1968). The riots in turn fueled further acceptance of militancy and radical action. In fact, Huey Newton (1973) reported that the Watts outbreak was the final precipitant to the founding of the Black Panther Party.

\section{Short-Term Contagion Effects}

Among the perspectives that focus on short-term effects, several analysts have entertained the notion of reinforcement effects, under which a riot in a particular city would increase the chances of another riot in the same city (Spilerman 1970; National Advisory Commission on Civil Disorders 1968). Hypotheses about reinforcement grew from observations that a riot tended to temporarily increase polarization between racial groups. After some riots, neighborhood and business protective associations formed, sales of guns increased, and considerable anger was expressed by blacks toward white police and by whites toward black rioters. The same factors could also have contributed to a contagion effect. Following a publicized riot in a particular city, tensions would increase not only in that city, but also in nearby areas. The Kerner commission observed such an effect following the Newark riot: "Reports of looting, sniping, fire, and death in Newark wove a web of tension over other Negro enclaves in northern New Jersey" (National Advisory Commission on Civil Disorders 1968, p. 38).

More important, however, well-publicized collective action provides other potential actors with an "occasion for deciding" (Oliver 1989). When a riot breaks out, people start discussing it and the issues that surround it. What caused the riot to occur? Was the act justified? What were the goals of those who rioted? Will the response to the riot forward those goals? Do I support the rioters? Should I participate in such collective behavior? What are the potential costs and benefits? These conversations occur not only on an informal personal basis, but also more systematically via news coverage and editorials. For weeks following the Watts riot, a large portion of space in Los Angeles newspapers with largely black readerships was devoted to discussing the riot and its aftermath (Crump 1966). In effect, the opportunity to debate these questions, informally and publicly, allows individuals to signal their level of willingness to participate.

The occasion-creating effect lasts only a short time for most observers. Once the riot is no longer novel and after most have had the opportunity to decide and to act, the effect tends to die away (Oliver 1989). Of course, 
American Journal of Sociology

if additional events quickly follow the first and each is well publicized, a cascading effect may cause more and more individuals to make the decision to riot, and events can, at least for a short time, build on one another. This pattern is thought to have driven the relatively short but intense period of rioting in 1967 that included the Newark and Detroit riots.

\section{Recent Diffusion Modeling}

Although adequate analytic methods for examining diffusion/contagion processes were not available during the riot wave of the 1960s, recent advances in diffusion modeling allow tests of a whole range of diffusion/ contagion hypotheses. Two related but distinct approaches have been taken to diffusion issues. The first approach focuses on spatial effects, which may provide evidence of social diffusion effects (Land and Deane 1992; Land, Deane, and Blau 1991; Tolnay 1995; Tolnay, Deane, and Beck 1996; Morenoff and Sampson 1997). Under this approach, the dependent variable is assumed to be affected not just by the usual kinds of predictors, but also by the value of the dependent variable in nearby areas.

In event history diffusion models, the diffusion process is modeled as a dynamic process in which prior adoptions are constantly changing their effects on the rate of adoption (Strang and Tuma 1993; Greve, Strang, and Tuma 1995). The amount of adoption is not measured across spatial units at any one time in order to predict adoption at any other particular time. Instead, prior adoption is accumulated as it occurs, and its influence changes to reflect this accumulation. Under event history then, diffusion models take on a considerably more dynamic character. Both spatial and temporal diffusion processes, as well as more complex combinations of the two, can be examined using these approaches.

In their relatively limited histories, both the spatial effects approach and the event history approach have produced evidence that contagion is operating in collective violence and protest waves. Tolnay, Deane, and Beck (1996) show spatial effects among lynching events in southern counties, although some of these effects are difficult to classify as diffusion since lynching events seem to depress rates of lynching in nearby counties. Using the event history approach, Soule (1997) found evidence of diffusion effects among a series of college antiapartheid shantytown protest in the 1980s (Strang and Soule [1998] provide a more thorough review of this and related work). Most directly related to the current piece, I (Myers 1996, 1997a, 1997b) used event history diffusion models to examine the racial riots of the 1960s for contagion effects. In these pieces, I produced evidence supporting several general contentions about riot contagion that reflect some of the concerns raised above. First, the results shows that 


\section{Collective Violence}

events accumulate in patterns that are consistent with classical diffusion models in which each subsequent event contributes to long-term changes in the rate of rioting. Second, I also showed that riots exhibit a shortterm contagion effect that fades over time, declines with distance from the riot, and is keyed to the severity of the contagious riot.

While this work demonstrates that diffusion was an important force in the riot wave, it leaves open a number of questions about inter-actor and inter-event influence within the riot wave. Beyond knowing that diffusion effects exist, it would be helpful to know more about the specific character of the diffusion process. In the present article, I take up three aspects of riots not previously examined in a diffusion context. Given the many citylevel analyses of rioting, one may ask if there are characteristics of a city or of its riot that make the riot more or less contagious to other actors. Second, when a riot occurs, some cities seem to be more likely to imitate than others. What factors might make one city more susceptible to influence than others? Third, when a social diffusion effect occurs, it must be carried by some kind of communication network. Without information about prior adoption acts (riots), potential adopters cannot imitate them. With respect to the riots of the 1960s, many have observed the important role the mass media played in spreading information about rioting, thereby contributing to the spread of rioting. I propose that a careful mapping of the mass media network will help to determine where prior riots will be the most contagious and therefore where future rioting is most likely to break out. To test these various hypotheses, I turn to the extension of event history diffusion models developed by Strang and Tuma (1993)_heterogeneous diffusion models.

\section{HETEROGENEOUS DIFFUSION MODELS}

In the history of social diffusion modeling, one concern has dominated the literature: the timing of adoption events (see reviews in Rogers [1995], Mahajan and Peterson [1985], and Valente [1995]). By focusing mainly on the accumulation of adopters over time, analysts were able to maintain key assumptions about homogeneity among actors, namely, that all actors had equivalent contact and that adopters maintained constant contagious influence after adopting. While these assumptions of spatial homogeneity and temporal homogeneity allowed substantial advances in the development of deterministic diffusion models, neither assumption is particularly plausible for most social processes. For example, spatial homogeneity is often violated because social communication networks are geographically concentrated, and therefore the probability of contact between pairs of actors differs. Furthermore, the salience of social events usually wanes as the events age, and temporal homogeneity is thus violated. 
American Journal of Sociology

Because eliminating these assumptions would allow considerably more detailed and useful analyses of diffusion, several analysts began translating diffusion models into an event history framework that focused on individual rates of adoption rather than cumulative counts of adoption events (Strang and Tuma 1993; Marsden and Poldony 1990; Hedstrom 1994; Greve, Strang, and Tuma 1995; Davis and Greve 1997; Soule and Zylan 1997; Myers 1997b). When diffusion processes are tested using event history, a full range of covariates indicating individual characteristics, relative spatial positions, and time decay of influence can be incorporated, and analysts have demonstrated the importance of each kind of heterogeneity in explaining the spread of social behavior.

As recently explicated by Strang and Tuma (1993; Strang 1995), event history diffusion models allow four specific types of diffusion related predictors: intrinsic characteristics, infectiousness, susceptibility, and proximity. Formally, the full model of these diffusion predictors is given by:

$$
\lambda_{n}(t)=\exp \left[\boldsymbol{\alpha} \mathbf{X}_{n}+\sum_{s \in \mathrm{S}(t)}\left(\beta V_{s}+\gamma W_{n}+\delta Z_{n s}\right)\right],
$$

where $\lambda_{n}(t)$ is the hazard of adoption for actor $n$ at time $t$; $\boldsymbol{\alpha}$ is a vector of parameter estimates for the effects of the $X_{n}$ vector of covariates describing either intrinsic characteristics of actor $n ; \beta$ is a vector of parameter estimates for the effects of the $V_{s}$ vector of covariates describing the infectiousness of actor $s$ as it influences all other actors by its adoption; $\gamma$ is a vector of parameter estimates for the effects of the $W_{n}$ vector of covariates describing the susceptibility of actor $n$ to influence from the group of prior adopters; $\boldsymbol{\delta}$ is a vector of parameter estimates for the effects of the $Z_{n s}$ vector of covariates describing the pairwise influence of actor $s$ on $n$ due to social or spatial proximity; and $\mathbf{S}(t)$ is the set of those actors who have adopted by time $t^{2}$

Intrinsic characteristics $\left(X_{n}\right)$ are those attributes of individual actors that increase or decrease their propensity to adopt, irrespective of the behavior of others. Intrinsic characteristics correspond closely to earlier research on rioting where city-level characteristics like population or local economic conditions were used to predict riot frequency and severity (e.g., Spilerman 1970, 1971, 1976; Carter 1983, 1986; Morgan and Clark 1973; Jiobu 1971; Lieske 1978; Olzak and Shanahan 1996). Because the focus of the current research is on contagion processes, these variables are viewed mainly as controls that provide a baseline model for comparison to diffusion formulations.

\footnotetext{
${ }^{2}$ More precisely, eq. (1) represents the multiplicative variant of Strang and Tuma's (1993) heterogeneous diffusion model. See Strang and Tuma (1993) and Greve, Strang, and Tuma (1995) for an explanation of the additive variant.
} 


\section{Collective Violence}

The second series of covariates in heterogeneous diffusion models are those that indicate the infectiousness of individual actors $\left(V_{s}\right)$. Infectiousness produces an estimate of how influential the individual actor's adoption act is on everyone else in the system. The usual approach is to identify some key characteristic(s) of individual actors that are thought to regulate infectiousness and multiply this characteristic by the number of times the actor has adopted. For example, Strang and Tuma (1993) used network centrality in their reanalysis of Coleman, Katz, and Menzel's (1966) Medical Innovation study, reasoning that centrality was tied to influence and thus that the behavior of more central actors would be more contagious. In terms of rioting, a characteristic of the actual event, severity, may be the most important determinant of infectiousness.

Susceptibility $\left(W_{n}\right)$ conveys how responsive an individual actor is when an adoption act occurs. In terms of the current study, when a riot occurs, susceptibility tells us how likely it is that a specific city will imitate and respond with its own riot. As with infectiousness, susceptibility must be tied to some characteristic of the individual actor. For example, I argue below that a city's susceptibility to influence from other riots is a function of the size of its black population.

The final type of predictor in the event history diffusion model is the proximity indicator. These covariates $\left(Z_{n s}\right)$ relate the level of influence of a previous adopter $(s)$ on each other actor $(n)$ in the system as a function of some measure of proximity. In some cases, a dichotomous indicator of influence is used, such as a tie in a network structure, (Strang and Tuma 1993) and in others, a continuous indicator of influence may be used, such as a functional transformation of physical distance (Myers 1996; 1997b). Both types of indicators will be invoked in the present analysis.

\section{HYPOTHESES ABOUT RIOT DIFFUSION}

Based on Strang and Tuma's diffusion model, I propose a number of hypotheses about riot contagion in the 1960s racial rioting wave. These hypotheses are represented by three general ideas reflecting the notions of heterogeneous infectiousness, susceptibility, and proximity. First, I propose that media attention bias contributed to the diffusion of riots. Some riots were more likely to attract media attention than others and as a result were more infectious than others. Second, I propose that cities were more or less receptive to contagious influence as a function of their population characteristics. Specifically, I expect that cities with larger black populations are more resistant to contagious influence than cities with small black populations. Third, I propose that the network of influence among cities was defined not only by the geographic position of cities, but also by proximity within the mass media distribution networks. 
American Journal of Sociology

Media Distribution and Media Selection Bias

Each of these notions of riot diffusion-infectiousness, susceptibility, and proximity-depends on the communication network among actors. If riot diffusion is to occur, information about recent riots must be transmitted, and the nature of the communication process will define both the communication network and the form of the diffusion process. When collective behavior in general, and collective violence in particular, are considered, the most important communication conduit is the mass media (Lipsky 1968). For riots, television broadcasts are particularly important (e.g., Stark et al. 1974; Spilerman 1970; Waddington 1992; Snyder and Kelly 1977). These broadcasts not only helped to spread a single riot within a city, but also escorted rioting and its accompanying rhetoric from one city to others.

The media network is far from a transparent conduit of information about rioting, however. Just as with any other type of news item, news media reports on protest and collective violence events are biased (e.g., Gans 1980; Herman and Chomsky 1988). Bias exists not only in the specific information reported about events, but also in whether the event is reported at all (Snyder and Kelly 1977; Danzger 1975; Mueller 1997; McCarthy, McPhail, and Smith 1996; McCarthy et al. 1998; Oliver and Myers 1999; Myers and Caniglia 2000). The issue of media selection bias has received considerable attention recently because so many important studies of collective protest have relied on newspaper accounts for their data. While recent studies have taken on the methodological issues surrounding newspaper data, less attention has been paid to the problem of how media selection bias may affect the actual movement trajectory. Because media coverage is so critical to the life of a protest movement, the bias in media coverage should have important ramifications for the diffusion of collective behavior.

The two most robust findings in the media bias line are, first, that news media are more likely to report events that involve larger numbers of people (McCarthy, McPhail, and Smith 1996; McCarthy et al. 1998; Oliver and Myers 1999; Oliver and Maney 1998) and, second, that events near the media source are more likely to be reported than those farther away (Snyder and Kelly 1977; Mueller 1997; Paige 1975; Franzosi 1987). Both of these findings are explained by the underlying newsworthiness of the event: those events that are more intense and involve more people are considerably more newsworthy than smaller events. In addition, the audience also helps determine newsworthiness. Because most of a newspaper or local television station's audience identifies with the city that produces the media, they create a demand for information about that city rather than outlying areas. The asymmetry in demand, then, produces an asym- 


\section{Collective Violence}

metric flow of information between large and small cities. Smaller cities depend on large cities as their media sources and receive a great deal of information from them. Conversely, those in large cities pay disproportionately less attention to events in smaller outlying areas. Compare Chicago and DeKalb, Illinois, for example. DeKalb residents depend heavily on Chicago television broadcasts and newspapers, but few people in Chicago receive media produced in DeKalb. This asymmetry in the flow of information produces a situation in which Chicago is a cultural center and cities such as DeKalb are satellites. These two newsworthiness factors, event severity and cultural centrality of the actor, point to a set of specific hypotheses regarding riot diffusion.

\section{Infectiousness and Riot Severity}

Long-term effects.-With respect to infectiousness, the main hypothesis is simply that the more severe a riot is, the more influence it will have on the future rate of rioting - that is, severe riots are more infectious than mild ones. Because media coverage is tied so tightly to the intensity of a collective event (McCarthy, McPhail, and Smith 1996; Mueller 1997; Snyder and Kelly 1977; Oliver and Myers 1999), it follows that large riots will receive more widespread and intense coverage and, as a result, be subject to considerably more imitation than small riots that receive little or only local coverage. This effect occurs first because imitation requires knowledge of prior events and their outcomes. Without media coverage, infectious influence will be severely curtailed. Furthermore, heavily reported severe events will in turn set in motion many of the long- and short-term effects discussed above: programs intended to address ghetto problems may be prodded forward; more blacks will experience personal positive reinforcement; more potential rioters will be exposed to the new protest tactic; and more will be confronted with an occasion to decide about joining the action.

To operationalize infectiousness due to riot severity, the severity of all riots that have previously occurred are summed. ${ }^{3}$ Formally, infectiousness at time $t$ is computed by:

$$
V_{(t)}=\sum_{a \in \mathbf{A}(t)} S_{(a)},
$$

where $\mathbf{A}(t)$ is the set of all adoptions (riots) that have occurred by time $t$, and $S$ is the severity of event $a$. It is apparent from this definition that infectiousness only varies over time and not over actors. At any given

${ }^{3}$ See the appendix for the construction of the severity indicator represented by $S_{(a)}$ in eq. (2). 


\section{American Journal of Sociology}

time, all actors experience the same degree of infectiousness (see Strang and Tuma 1993; Strang 1995). ${ }^{4}$

This straightforward construction of infectiousness means it will be monotonically increasing over the course of the study. ${ }^{5}$ And because we know the riot rate increases during the first half of the riot wave and decreases during the second half, it is somewhat implausible that a linear relationship between infectiousness and the riot hazard exists. As a result, I hypothesize that infectiousness may have a curvilinear effect on the riot hazard. The logic of this hypothesis follows from classic diffusion models in which the rate of adoption is slow at the beginning of the cycle, peaks in the middle of the cycle, and then returns to near zero toward the end of the wave. The overall linear trend of this cycle necessarily approximates zero (see Mahajan and Peterson [1985] and Myers [1996, 1997b] for more detail on this point). ${ }^{6}$ When we examine the dependence of the riot rate on the raw number of prior events (drawing a direct parallel to classical diffusion analysis, see Strang and Tuma [1993] and Mahajan and Peterson [1985]), we should expect this dependence to take a curvilinear form. That is, each additional event in the first half of the adoption cycle increases the probability of further rioting, and each additional event in the second half of the cycle decreases future rioting.

This same logic can be applied to infectiousness. Instead of simply counting events, however, each event's contribution to infectiousness is qualified by its severity. Severe events contribute relatively more influence

\footnotetext{
${ }^{4}$ In most diffusion work, contagion is presumed to affect only those who have not previously adopted the behavior. This approach is taken because adoption is usually viewed as a one-time event for each actor. That is, once the actor has adopted, he or she can no longer be subject to contagious influence because he or she can no longer adopt. But when collective violence is considered, adoption is not an absorbing state because actors may adopt repeatedly. Therefore, adopting and becoming a spreader does not force the actor to relinquish his or her status as a potential adopter. This requires a slight alteration in the notion of infectiousness such that the infectiousness produced by an adoption act is felt by all other actors, whether or not they have previously adopted.

${ }^{5}$ Because infectiousness is the sum of the severity of all prior riots, it is necessarily collinear with the simple count of prior riots. There is a substantial difference between the riot count and infectiousness however. Over time, the count of prior events and infectiousness are both rising, but infectiousness rises relatively more when a severe event occurs. If an increase in the riot rate accompanies that rise in infectiousness, then more severe riots have been more infectious (that is, have had more influence) than less severe ones.

${ }^{6}$ A number of diffusion analyses (e.g., Strang 1990, 1991; Strang and Tuma 1993; Soule 1997; Soule and Zylan 1997) have found significant positive linear effects of the count of prior events (sometimes called the "contagion intercept"), but these trends exist only because the diffusion process was truncated either by historical circumstances or by the termination of observation. If the entire diffusion cycle is observed, the linear effect of the prior count of events should not be significant.
} 


\section{Collective Violence}

than less severe ones. While this pattern forms a reasonable hypothesis for the upswing of the riot cycle, it may be reversed as the cycle wanes. In other words, just as each event reduces the rate of future rioting on the downswing of the cycle, more severe events may cause an even greater reduction of rioting compared to less severe events. This pattern may occur because the positive reinforcements for rioting eventually reverse. For example, if repression is increasing with each individual riot, and severity determines the amount of repression, then severe riots will decelerate rioting more than mild outbreaks. It is well known that repression increased markedly during the latter half of the riot wave, and these repressive tactics (such as deploying the National Guard) were targeted much more at large incidents than small skirmishes (McAdam 1982, 1983).

Short-term effects.-Beyond the long-term trends related to infectiousness, there may also be short-term effects resulting from time decay. Time decay is at issue when, at any point in time, a recent riot is more influential than earlier riots that have faded from memory. I have previously demonstrated that this kind of temporal heterogeneity is an important aspect of riot diffusion (Myers 1996), and just as a riot's overall contagion fades over time, so too might the additional infectiousness contributed by the riot's level of severity. I took two approaches to operationalizing this shortterm variant of infectiousness. ${ }^{7}$ First, I allowed each riot to make its contribution to infectiousness (based on its severity) for only one week. Once a riot was older than one week, its contribution to infectiousness was changed to zero. ${ }^{8}$ Formally,

$$
V_{(t)}=\sum_{a \in \mathbf{A}(t)} S_{(a)} m_{T(a), T \leq t-7},
$$

where $m$ is a dummy variable indicating if the time $T$ of adoption $a$ was at most seven days before time $t$. This model is overly simplistic in that a riot is assumed to have a constant effect for one week and then no effect whatsoever following that week. Therefore, I also constructed a version in which the infectiousness decays gradually over the course of one week. This effect is achieved by dividing the severity effect by its age in days:

\footnotetext{
${ }^{7}$ The short-term infectiousness effects operationalized by eqq. (3) and (4) are equivalent to the effects of severity located by Myers (1996). However, that treatment neglected several important controls, did not address the long-term variants of infectiousness, and did not conceptualize severity as part of the infectiousness construct in the Strang and Tuma diffusion model. Therefore, this effect is reevaluated as part of the current analysis.

${ }^{8}$ Other time periods (two weeks, four weeks, and eight weeks) were examined, but none provided improved fit over the one-week construction
} 
American Journal of Sociology

$$
V_{(t)}=\sum_{a \in \mathbf{A}(t)} \frac{S_{(a)} m_{T(a) T \leq t-7}}{t-T(a)} .
$$

In all tests, the gradual version completely superseded the constant-effect version, and therefore only the time-decay version is presented.

\section{Susceptibility and Population Size}

Inasmuch as riots differ in terms of their infectiousness, a more critical diffusion issue may be susceptibility. Are there differences in cities that predict how likely they are to imitate others that have experienced riots? Of course, cities have differences in their intrinsic propensities to riot, tied to, for example, black population size (e.g., Spilerman 1970, 1971; Myers $1997 b$ ). But beyond such factors, the susceptibility question asks whether some cities are more likely to react to the behavior of others, irrespective of their inherent propensity to riot. While infectiousness may depend either on the characteristics of adoption events or of adopting actors, susceptibility stems from the characteristics of potential actors (in this case, cities). Given that in past studies the size of the black population has been such a prominent intrinsic characteristic predicting rioting, it may be an appropriate index of susceptibility as well. In other words, in addition to a greater black population increasing the propensity to riot, larger black populations may also be more responsive to prior riots.

While this may be a reasonable progression of logic, I argue for the opposite relationship. That is, larger black populations are less susceptible to contagion from prior riots. If one is concerned with the intrinsic propensity to riot, more people obviously increase the baseline probability of rioting. Once this propensity is controlled, however, it is not clear that greater numbers of people should be more responsive to external events. In fact, typical information flow patterns dictate the opposite. Beyond the elements of media bias reviewed above, one additional finding has been that events in larger cities are reported more often than those in smaller cities (Tilly 1969; Snyder and Kelly 1977). This pattern is not limited to collective violence or riots, of course, but is applicable to all cultural, civic, and political activities that fill newspapers and airwaves. Not only do more of these events occur in large cities, but media outlets and personnel are concentrated in larger cities, intensifying the coverage of big-city events because of easier access to mass media (Danzger 1975). Smaller cities around the hub become satellites, as their events have relatively little salience in hub cities. At the same time, hub events have considerable cultural salience in satellite cities. This asymmetric pattern of salience suggests a diffusion susceptibility pattern, where larger cities should be 


\section{Collective Violence}

less responsive to the average external event and smaller cities should be more responsive.

For the riots in question, it is the black population (rather than the total population) that is the adopting unit and therefore the unit susceptible to the influence. Therefore the hypothesis I test is that susceptibility due to black population size is negatively related to the rate of rioting.

Susceptibility for a particular city at any point in time is operationalized by multiplying a city's nonwhite population size by the total number of riots that have occurred prior to that point in time (see Strang and Tuma 1993; Strang 1995 for additional detail on the operationalization of susceptibility). ${ }^{9}$ Formally, susceptibility is computed by:

$$
W_{n}=P_{n}|\mathbf{A}(t)|,
$$

where $P$ is the nonwhite population of city $n$ and $|\mathbf{A}(t)|$ is the total number of events that has occurred by time $t$. Equation (5) provides the susceptibility covariate used in the long-term analysis. A time-decay version following the method used for infectiousness (eq. [4]) was also constructed for use in the analysis of short-term riot contagion.

\section{Proximity in a Mass Media Distribution Network}

Although the mass media is absolutely critical for the diffusion of collective violence and protest, its influence is limited by its distribution. Local newspapers and television broadcasts can only be expected to spread protest in places where people read those newspapers and watch those broadcasts. The distribution of mass media, then, provides a link among collective actors, and these links can be used to define a network among units-in this case, cities. Cities that receive the same newspapers and television stations have strong links to each other because they receive the same information and constitute a singular target audience for the media they receive.

It is not, however, necessarily the case that information flows equally among all members of the communication network. Media-rich cities may be primary providers of information, while media-poor cities become mainly consumers. Cities then may be more or less influential in the network, not just because of the number of ties they have to other cities, but because they control the media mechanisms that service the network. Given this possibility for asymmetry in mass media resources, I consider

${ }^{9}$ Nonwhite population size rather than black population size is used to allow interpolation from 1960 to 1970 . Black population size in 1960 is not readily available for all cities in the study. The correlation between nonwhite population and black population in 1970 for all cities in the study is $r=.98$. 


\section{American Journal of Sociology}

two possible network structures to define the flow of information about rioting. The first, the responsive network structure, presumes equivalence among connected cities-all connected cities receive equal information about riots that occur in connected cities. The second, the asymmetric network structure, presumes that information about riots occurring in media-rich cities is distributed to all connected cities but that information about riots in media-poor cities is not because they do not have the capacity to broadcast their news to other cities. ${ }^{10}$

Because television broadcasts were so critical to the spread of rioting in the 1960s, both media network structures were constructed using information about television broadcasts. To begin this process, each city was assigned a dummy code depending on whether it had at least one network affiliated (NBC, CBS, or ABC) television station in $1968 .{ }^{11} \mathrm{In}$ addition, the broadcast area of each station was calculated using a circle with a 60-mile radius around the city in which the television station was located. ${ }^{12}$

Using this information, two different connection matrices were constructed. The responsive network posits that all cities within the broadcast range of a single television station affect one another. If a riot occurs within the broadcast area of any television station, this network structure assumes that the television station will report it and all cities within its broadcast radius will receive the report. Thus, all cities within the broadcast area have direct connections through which contagious influence may flow. Cities outside a particular broadcast area are assumed to have no contagious influence on each other.

The asymmetric media network structure is similar to the responsive

${ }^{10}$ A series of network structures based on geographic regions was also examined. These network structures assumed that cities were connected only to those within their own region and reflected the possibility that cultural circumstances within regions (with respect to race relations, for example) made riots more contagious within the region than outside of it. Once physical distance was controlled, no effects of these network models could be detected. Therefore, the results are not detailed herein.

${ }^{11}$ This information was tabulated from the 1968-69 edition of the Television Factbook (Television Digest, Inc., 1968). It is, of course, possible that television stations were founded, failed, or gained and lost affiliate status during the study period-changes that would effect the network structure. Given the relatively short period of this study and the general stability of affiliate status during this period, however, the use of a single point in time (1968) appears to produce little distortion. Additional detail justifying this procedure is available from the author.

${ }^{12}$ Although station power and local geographic characteristics condition the reach of each station, a 60-mile radius around a VHF station is generally adequate to ensure Grade A service as defined by the Federal Communication Commission. Grade A service means that the quality of the picture is satisfactory to the median observer at least $90 \%$ of the time for at least $70 \%$ of the receiving locations within the broadcast radius (see Television Digest, Inc. [1968] for more detail). 


\section{Collective Violence}

network except that it assumes a much stronger media attention bias. In this model, events that occur in cities without television stations are treated as relatively invisible compared to those riots occurring in mediarich cities. The asymmetric network then is defined such that all cities within a television station's broadcast radius receive information about riots that occur in the station's home city, but no city receives information about riots that occur in cities that do not have television stations. The assumption underlying this model is that cities without television stations are easily infected but are unlikely to infect others. ${ }^{13}$

Once the network structure has been identified, usual indicators of the relative position of each actor within the structure can be computed. For example, most network analyses identify centrality as a key characteristic of each actor. Centrality conveys each actor's relative influence in the social system as a function of its ties to other actors. The more ties, the more central and influential the actor. Centrality has been a key player in the understanding of diffusion through networks and is usually operationalized as a simple or weighted count of the number of ties each actor has to others (Knoke and Kulinski 1982; Strang and Tuma 1993; Burt 1987). In the present study, the number of ties a city has to others via one of the proposed network structures could also be an important issue, but less because of how influential that city may be, and more because of how influenced it may be. The more ties a city has, the more likely it is to come in contact with a contagious riot, thereby increasing the likelihood of a riot breaking out. However, it is not centrality per se that operates to cause this increased likelihood of adoption. Rather it is the actor's indegree (Knoke and Kuklinski 1982), the number of other actors that influence it, that is pivotal.

In the responsive network structures described above, the distinction between indegree and centrality is meaningless, because in symmetric networks, indegree and centrality are equal. The distinction is important though in the asymmetric network structure, because a city's indegree and outdegree may differ. A city with no television station has an outdegree of zero, but if it falls within the broadcast radius of one or more cities with television stations, its indegree is $>0$. Likewise, any city that has a television station has an outdegree $\geq 1 .{ }^{14} \mathrm{I}$ test and discuss indegree

\footnotetext{
${ }^{13}$ This hypothesis does not, of course, imply that riots in cities without television stations have no contagious effect at all; rather, it means that they have no effect net of the contagion variables tested in these models, while those in cities with television stations do have additional influence not captured by other variables.

${ }^{14}$ Because a riot in a city can affect future rioting in that same city, I allow ties to the self. This means, e.g., that if there are no other cities in the broadcast radius, indegree $=$ outdegree $=1$.
} 


\section{American Journal of Sociology}

in the results section, although for the responsive media network, the tests are equivalent to testing centrality.

\section{DATA AND MODEL ESTIMATION}

The riot data used to test for these diffusion processes was collected by Carter (1983) and contains all riots that occurred in the United States from 1964 through 1971. In compiling these data, Carter used the operational definition of "civil disorder" forwarded by Spilerman (1970). This definition of civil disorder states that each incident must have involved at least 30 people and included some interpersonal violence or destruction of property. Some specific types of disorders were not tabulated by Spilerman or Carter (such as events focused on institutional conflicts and those that arose as a result of a planned protest). The result was a fairly homogeneous set of spontaneous, black-initiated events. ${ }^{15}$ Carter compiled information on these events from the Congressional Quarterly's Civil Disorder Chronology, the New York Times Index, the Report of the National Advisory Commission on Civil Disorders, Brandeis University Lemberg Center for the Study of Violence's Riot Data Review, unpublished material from the Lemberg Center, the U. S. Senate's compilation reported in Riots, Civil, and Criminal Disorders, and original newspaper articles from the New York Times and the Washington Post. ${ }^{16}$ Carter located a total of 752 riots occurring in 313 cities during the study period. ${ }^{17}$ Carter also collected five indicators of riot severity for each riot: the number of arrests, the number injured, the number of arsons, the number killed, and the duration of the riot in days. These were combined into a composite severity index for the present analysis (see the appendix for details).

A set of cities that did not experience riots was added to the data set

${ }^{15}$ More details on these categories of events and the rationale for the selection criteria are given in Spilerman (1970).

${ }^{16}$ Carter's care in compiling these data identified many riots that were not detected by others. For example, in 1968 alone, Carter identified 289 riots compared to only 141 detected by Spilerman (1970), despite using identical selection criteria. Carter also did not restrict his attention to a subset of cities as many others have (e.g. Spilerman 1970, 1971, 1976; Myers 1997b; Olzak and Shanahan 1996; Olzak, Shanahan, and McEneaney 1996; Jiobu 1971). Limiting analysis to a subset of cities (based primarily on population size) was necessary in these studies because indicators of theoretical concepts were not available for many of the smaller cities. Unfortunately, the result was that many riots were either ignored or not detected. For example, of the riots Carter located, nearly $20 \%$ took place in cities that had been excluded from Spilerman's original analysis.

${ }^{17}$ The current analysis eliminates one of two distinct riots that occurred on July 18, 1964, in New York City. Computation is considerably simplified by assuming that no more than one riot could occur in one city on a single day, and the singular exception is unlikely to have any substantive impact. 


\section{Collective Violence}

for purpose of limiting sample selection bias. Each of these 200 U.S. cities had populations of at least 25,000 and had nonwhite populations of at least 1,000 (see esp. Spilerman [1970, 1971] for supportive rationale of this criteria).

The diffusion models herein can be straightforwardly estimated using a number of standard event history models, and I employ partiallikelihood estimation herein (Cox 1972). Cox regression does not require the analyst to specify the form of the baseline hazard, thereby making the maximization procedure dependent only on the estimated values of the hypothesized covariates. The coefficients generated can be interpreted by taking $\mathrm{e}^{\mathrm{b}}$, which produces the amount by which the hazard is multiplied for each unit increase in the related independent variable. ${ }^{18}$

Because analysis of collective violence demands inclusion of repeated observations on the same unit, and it is unlikely that all sources of intraunit dependence are accounted for in estimated models, unobserved heterogeneity may introduce a downward bias in standard error estimates (Allison 1984). In the present data, 160 of 513 cities experienced at least two riots, making the analysis susceptible to this problem. Therefore, a control variable, the number of prior riots that have occurred in a city, was introduced in all models. Including variables that represent the prior history of the individual unit is a practical procedure that minimizes the effects due to correlation within the same city and does not demand the restrictive assumptions of more general methods of correcting for unobserved heterogeneity (Allison 1984).

\section{RESULTS}

Infectiousness and Susceptibility in the Long Term

Models in table 1 test the riot data for differential infectiousness due to riot severity and differential susceptibility due to black population size. The first model in the table simply provides a baseline model against which to compare subsequent models. In addition to the control for prior rioting in a city, this model also contains two variables (nonwhite population and a dummy variable for cities in the south) that represent the intrinsic properties vector of the heterogeneous diffusion model. The effects of these variables are completely consistent with earlier research on these riots. Black population size is positively related to the riot hazard,

${ }^{18}$ Models presented herein were also estimated using parametric models, but the minute differences do not warrant further discussion. 


\section{American Journal of Sociology}

TABLE 1

Partial-Likelihood Estimates of the Effects of Infectiousness and SusCEPTIBILITY ON THE Riot HAZARD

\begin{tabular}{|c|c|c|c|c|}
\hline & Model 1 & Model 2 & Model 3 & Model 4 \\
\hline \multicolumn{5}{|l|}{ Control variables: } \\
\hline $\begin{array}{l}\text { In of nonwhite } \\
\text { population }\end{array}$ & $.466^{* * *}$ & $.467^{* * *}$ & $.462^{* * * *}$ & $.652^{* * *}$ \\
\hline & $(.029)$ & $(.029)$ & $(.029)$ & $(.043)$ \\
\hline South $\ldots \ldots \ldots \ldots$ & $\begin{array}{l}-.490 * * * \\
(.084)\end{array}$ & $\begin{array}{l}-.489^{* * *} \\
(.084)\end{array}$ & $\begin{array}{l}-.478^{* * * *} \\
(.084)\end{array}$ & $\begin{array}{l}-.420 * * * \\
(.085)\end{array}$ \\
\hline \multicolumn{5}{|l|}{ History of rioting } \\
\hline (control) ......... & $\begin{array}{r}-.0026 \\
(.020)\end{array}$ & $\begin{array}{r}-.0061 \\
(.021)\end{array}$ & $\begin{array}{r}-.0020 \\
(.021)\end{array}$ & $\begin{array}{l}.0555 \\
(.023)\end{array}$ \\
\hline \multicolumn{5}{|l|}{ CR (intercept): } \\
\hline $\mathrm{CR}$ at $t(\mathrm{CR}) \ldots \ldots$ & $\begin{array}{l}.0139^{* * *} \\
(.00082)\end{array}$ & $\begin{array}{c}-.0033 \\
(.0094)\end{array}$ & $\begin{array}{r}-.0142 \\
(.011)\end{array}$ & $\begin{array}{r}-.0055 \\
(.011)\end{array}$ \\
\hline $\mathrm{CR}^{2} \times 10^{-3} \ldots \ldots$ & $\begin{array}{l}-.0187^{* * * *} \\
(.0012)\end{array}$ & $\begin{array}{l}-.0162^{* * *} \\
(.0025)\end{array}$ & $\begin{array}{l}.0140 \\
(.010)\end{array}$ & $\begin{array}{l}.0068 \\
(.010)\end{array}$ \\
\hline \multicolumn{5}{|l|}{$\begin{array}{c}\text { Infectiousness and } \\
\text { susceptibility } \\
\text { (long term): }\end{array}$} \\
\hline Infectiousness $\ldots$. & & $\begin{array}{l}.0132 \\
(.012)\end{array}$ & $\begin{array}{l}.0426^{* *} \\
(.015)\end{array}$ & $\begin{array}{l}.0383^{* *} \\
(.015)\end{array}$ \\
\hline \multicolumn{5}{|l|}{ Infectiousness ${ }^{2} x$} \\
\hline $10^{-4} \ldots \ldots \ldots \ldots$ & & & $\begin{array}{l}-.728^{* *} \\
(.24)\end{array}$ & $\begin{array}{r}-.549^{*} \\
(.242)\end{array}$ \\
\hline $\begin{array}{c}\text { Susceptibility } \times \\
10^{-3} \ldots \ldots \ldots \ldots\end{array}$ & & & & $\begin{array}{l}-.653^{* * *} \\
(.11)\end{array}$ \\
\hline Model $\chi^{2}$ & 814.20 & 815.45 & 824.43 & 859.95 \\
\hline$d f \ldots \ldots \ldots . . .$. & 5 & 6 & 7 & 8 \\
\hline
\end{tabular}

and southern location is negatively related, meaning that less rioting occurred in southern cities. ${ }^{19}$

In addition, a curvilinear construction of the total number of prior riots is included to capture the general diffusive effect of riots as they accu-

${ }^{19}$ As with any analysis of contagion, it is possible that the effects located in this analysis are exaggerated due to collinearity with unobserved structural variables. This threat is reduced to some degree in the present analysis because of the large number of studies that have attempted and failed to identify city characteristics associated with rioting. If the size of the black population and region are controlled in the manner described, it is very difficult to find any additional structural characteristics of cities that contribute to the riot rate, much less ones that could have even a fraction of the power of the diffusion analysis that follows. 


\section{Collective Violence}

mulate. Consonant with classical diffusion models, each additional riot increases the riot rate during the first half of the riot cycle, and each additional riot decreases the riot rate in the second half. Detailed implications of these findings are discussed elsewhere (Spilerman 1970; McPhail 1994; Myers 1996, 1997b; Useem 1998).

In model 2, the linear version of the infectiousness indicator is tested. Here, the hypothesis states that, as severity accumulates over the course of the entire wave, rioting will increase as a result. For reasons discussed above, this hypothesis is not particularly plausible, and no support is found in the results. Model 3 uses a curvilinear construction of the infectiousness indicator, testing the notion that severe riots further increase the riot rate on the upswing of the riot cycle and further decrease it on the downswing. This idea is supported by the data. In concert with the notions of contagion and exhaustion discussed in prior work (e.g., Olzak 1987 , 1992), it appears that riot visibility partially controls the trajectory of the riot wave but has different effects depending on what point in the cycle is observed. Despite the significance of infectiousness in this particular model, the importance of these results should not be overstated because the effects are not extremely powerful and collinearity between this long-term construction and the temporally limited variant of infectiousness (presented below) suggests that the infectiousness effect for riots is primarily a short-term process.

The most substantial results given in table 1 are those of model 4 , which tests the hypothesis that cities differ in how much they are influenced by other riots and that these differences are a function of the black population size in the city. The results are straightforwardly supportive of the hypothesis. There is a negative significant relationship between susceptibility and the riot hazard. This finding simply means that cities with smaller black populations are much more susceptible to influence from prior rioting than cities with larger black populations. ${ }^{20}$ This finding strongly supports the influence model described above and further suggests the importance of asymmetry in influence among cities with different-size black populations.

\section{Infectiousness and Susceptibility in the Short Term}

To test hypotheses about the short-term effects of infectiousness due to severity and susceptibility due to black population size, I use the time-

${ }^{20}$ Susceptibility can also be viewed as an interaction between the nonwhite population of a city and the cumulative number of riots. Under this alternative conception, the interpretation of the results are the same. The reaction to accumulating riots is conditional on levels of nonwhite population size (and vice versa). 


\section{American Journal of Sociology}

decay operationalizations of these concepts discussed above. Before proceeding, though, it is necessary to include additional controls that were not present in the long-term analysis. First, because I am testing for shortterm effects, it is necessary to control for other sources of event clustering. In particular, it is well known that rioting peaked each summer and waned each winter within the larger riot cycle. To prevent this weather-related clustering from being misinterpreted as short-term contagion, I enter a curvilinear seasonal trend variable, the cumulative count of riots within each year, as an additional control. ${ }^{21}$ Second, because the infectiousness and susceptibility covariates implicitly incorporate both the number of riots in the prior one-week and time decay of influence, both of these effects must be controlled in order to ascertain the additional effects of infectiousness or susceptibility. Likewise, when testing for effects of networks that are geographically concentrated, results will be considerably more compelling if effects can be found beyond the effect of simple distance. Therefore, the distance between a contagious riot and each city is entered in anticipation of these network tests.

The results of the two models in table 2 demonstrate that infectiousness is extremely important for predicting rioting in the week following any particular riot, even above a large number of control variables. The more severe the rioting has been in the past week, the more infectious it is. For every one-point increase in short-term infectiousness, the hazard of rioting increases by over $35 \%$. This amounts to an $80 \%$ increase in the hazard over a one standard deviation unit increase in infectiousness. Susceptibility, on the other hand, does not appear to have a short-term component. Not only is the estimated coefficient nonsignificant, but the results for the long-term variant are unaffected. Therefore, the difference in receptiveness among cities due to their black population size is not a temporally heterogeneous effect.

\section{Network Proximity in the Long Term}

Table 3 reports the results of the network models using the responsive media network and the asymmetric media network, each building on table 1 , model 4 as a baseline. ${ }^{22}$ The first test is concerned with the number of ties a city has to other cities via the mass media networks. The indegree

\footnotetext{
${ }^{21}$ Because the number of riots is different each year, this covariate is constructed as the cumulative proportion of riots at any given point within a single year. This alternative construction allows the use of a single covariate to capture the repeated trend and prevents overemphasis of years that had extremely high numbers of riots.

${ }^{22}$ To save space, the coefficients associated with the covariates in model 4 of table 1 are not presented. However, they are completely consistent with those reported in table 1 , and no additional discussion is warranted.
} 
TABLE 2

Short-Term Effects of Infectiousness and Susceptibility on THE RIOT HAZARD

\begin{tabular}{|c|c|c|}
\hline & Model 1 & Model 2 \\
\hline \multicolumn{3}{|l|}{ Control variables: } \\
\hline ln of nonwhite population $\ldots$ & $\begin{array}{l}.668^{* * *} \\
(.044)\end{array}$ & $\begin{array}{l}.668^{* * *} \\
(.044)\end{array}$ \\
\hline South . & $\begin{array}{l}-.407^{* * *} \\
(.085)\end{array}$ & $\begin{array}{l}-.405^{* * *} \\
(.085)\end{array}$ \\
\hline History of rioting (control) & $\begin{array}{l}.0595^{*} \\
(.024)\end{array}$ & $\begin{array}{l}.0616^{*} \\
(.024)\end{array}$ \\
\hline \multicolumn{3}{|l|}{ CR counts: } \\
\hline $\mathrm{CR}$ at $t(\mathrm{CR}) \ldots$ & $\begin{array}{l}.0661^{* * * *} \\
(.013)\end{array}$ & $\begin{array}{l}.0409^{* * * *} \\
(.013)\end{array}$ \\
\hline $\mathrm{CR}^{2} \times 10^{-3} \ldots$ & $\begin{array}{l}.0143 \\
(.013)\end{array}$ & $\begin{array}{c}.0162 \\
(.012)\end{array}$ \\
\hline $\mathrm{CR}$ within $\mathrm{CY} \quad \ldots \ldots \ldots \ldots$ & $\begin{array}{l}8.32^{* * *} \\
(.67)\end{array}$ & $\begin{array}{l}8.65^{* * * *} \\
(.68)\end{array}$ \\
\hline $\mathrm{CY}^{2} \times 10^{-3} \ldots \ldots \ldots \ldots \ldots \ldots$ & $\begin{array}{l}-7.78^{* * * *} \\
\quad(.62)\end{array}$ & $\begin{array}{c}-8.20^{* * * *} \\
(.63)\end{array}$ \\
\hline \multicolumn{3}{|l|}{$\begin{array}{l}\text { Infectiousness and susceptibility } \\
\text { (long term): }\end{array}$} \\
\hline Infectiousness $\ldots \ldots \ldots \ldots \ldots$ & $\begin{array}{l}-.0574^{* *} \\
(.018)\end{array}$ & $\begin{array}{c}-.0191 \\
(.017)\end{array}$ \\
\hline Infectiousness $^{2} \times 10^{-4} \ldots \ldots$ & $\begin{array}{r}-.325 \\
(.29)\end{array}$ & $\begin{array}{c}-1.02^{* * *} \\
(.27)\end{array}$ \\
\hline Susceptibility $\times 10^{-3} \ldots \ldots \ldots$ & $\begin{array}{l}-.676^{* * *} \\
(.11)\end{array}$ & $\begin{array}{l}-.689^{* * * *} \\
(.11)\end{array}$ \\
\hline \multicolumn{3}{|l|}{$\begin{array}{l}\text { Short-term diffusion (riots in } \\
\text { past week): }\end{array}$} \\
\hline$N$ of riots $\ldots \ldots \ldots \ldots \ldots \ldots$ & $\begin{array}{r}-.0118^{*} \\
(.0052)\end{array}$ & $\begin{array}{l}-.0148^{* *} \\
(.0049)\end{array}$ \\
\hline Time decay $\ldots . . . . .$. & $\begin{array}{l}-.303^{* * * *} \\
(.050)\end{array}$ & $\begin{aligned}-.0689 \\
(.045)\end{aligned}$ \\
\hline Distance decay $^{\mathrm{a}} \ldots \ldots \ldots \ldots$ & $\begin{array}{l}.167^{* * * *} \\
(.038)\end{array}$ & $\begin{array}{l}.161^{* * *} \\
(.037)\end{array}$ \\
\hline Infectiousness ${ }^{\mathrm{a}}$. & $\begin{array}{l}.306^{* * *} \\
(.033)\end{array}$ & \\
\hline Susceptibility $^{\mathrm{a}} \times 10^{-3} \ldots \ldots \ldots$ & & $\begin{array}{l}.667 \\
(1.9)\end{array}$ \\
\hline Model $\chi^{2} \ldots \ldots \ldots \ldots \ldots \ldots$ & $1,357.53$ & $1,283.48$ \\
\hline$d f \ldots \ldots \ldots \ldots \ldots \ldots \ldots \ldots \ldots$ & 14 & 14 \\
\hline
\end{tabular}


American Journal of Sociology

TABLE 3

Network Proximity Effects on the Riot Hazard

\begin{tabular}{|c|c|c|c|c|c|c|}
\hline & \multicolumn{6}{|c|}{ MODEL $^{a}$} \\
\hline & $1-\mathrm{r}$ & $2-r$ & $3-r$ & $1-\mathrm{a}$ & $2-a$ & $3-a$ \\
\hline Indegree $\ldots \ldots$. & $\begin{array}{r}-.00421 \\
(.0055)\end{array}$ & & & $\begin{array}{l}.0285 \\
(.027)\end{array}$ & & \\
\hline PR ........... & & $\begin{array}{r}-.00328 \\
(.0047)\end{array}$ & $\begin{array}{c}.00861 \\
(.0098)\end{array}$ & & $\begin{array}{c}.00271 \\
(.0074)\end{array}$ & $\begin{array}{l}.0669^{* * * *} \\
(.019)\end{array}$ \\
\hline $\mathrm{PR}^{2} \times 10^{-3} \ldots$ & & & $\begin{array}{c}-.215 \\
(.16)\end{array}$ & & & $\begin{array}{c}-2.65^{* * * *} \\
(.76)\end{array}$ \\
\hline Model $\chi^{2} \ldots \ldots$ & 860.55 & 860.46 & 862.38 & 861.06 & 860.09 & 874.16 \\
\hline$d f \ldots$ & 9 & 9 & 10 & 9 & 9 & 10 \\
\hline
\end{tabular}

NoTE. - SEs are given in parentheses. PR indicates proximal riots.

a Models marked by "r" indicate "responsive media network"; models marked by "a" indicate "asymmetric media network."

$* P<.05$.

$* * P<.01$

*** $P<.001$, two-tailed tests.

is hypothesized to increase rioting because of a greater chance of exposure to other riots via higher numbers of network connections. Unlike some prior network diffusion analyses (e.g., Coleman, Katz, and Menzel 1966; Strang and Tuma 1993), indegree is completely ineffective in predicting riots. The estimated coefficients are nonsignificant in both tests (model 1-r and model 1-a).

The second network diffusion notion tested is that an actor is more responsive to adoption events that occur to directly connected others than to unconnected others. This means that if a city experiences a riot and a second city has a tie to the riot city via the mass media network, then that city may be more likely to riot. As the number of riots accumulate in a city over time, standard diffusion models predict that the chances of a riot in connected cities will increase. The results given in model 2-r and 2 -a show that this is not the case. For both hypothesized network structures, the accumulation of proximal riots has no significant effect on the riot hazard.

These results do not necessarily mean that proximal riots have no influence. The effects may not be apparent for two reasons. First, the influence of proximal riots may be time-limited instead of cumulative (taken up further below). Second, as was the case with the overall cumulative riot count and with infectiousness, the number of proximal riots may have a different effect on the upswing of the riot cycle than on the decline. Many riots nearby may increase the likelihood of rioting at first, but as support for rioting decreases or repression increases on the downswing of the cycle, additional proximal riots may further decelerate the process. 


\section{Collective Violence}

As reported in model 3-r, the curvilinear construction of proximal riot count is ineffective for the responsive media network. The story is different, though, when the asymmetric media network is examined. Consistent with expectations, a significant curvilinear relationship between past rioting in the asymmetric media network and the future riot rate does exist (model 3-a). This means that, initially, riots occurring in cities with television stations had a positive influence on rioting in connected cities, but over time, as the riots began to accumulate, they eventually had a negative impact on the riot rate. Nevertheless, these effects should not be overemphasized until the short-term versions are examined.

\section{Network Proximity in the Short Term}

Because riots are likely to lose their contagious capacity over time, temporal heterogeneity comes into play under network influence models. Riots occurring to proximal others may increase the likelihood of rioting, but that effect may last only a short time as the collective memory of a riot and its immediate salience wane. Therefore, I constructed time-decaying versions of the network proximity variables following the same procedure used for the time-decaying variants of infectiousness and susceptibility. As before, the effect of each proximal riot decays each day for seven days and makes no contribution thereafter. This covariate was calculated for both hypothesized network structures and individually added to the model represented in model 3 -a of table 3 . The results are reported in table 4, models 1 and 2, where it is apparent that each is an extremely powerful predictor of future rioting. With respect to the responsive network, when a riot occurs, the chances of a riot occurring in a connected city the next day are increased by nearly $150 \%$. Under the asymmetric network, if a riot occurs in a city with a television station, the chances of a riot occurring the next day in a connected city is nearly quadrupled. The table also reveals that the long-term effects of proximal riots reported in table 3 for the asymmetric media network are strongly collinear with the short-term media network effects and, in fact, have become nonsignificant in models 1 and 2.

Before accepting the apparent importance of short-term network effects reported in table 4, it is again necessary to consider additional controls. Given their construction, both network proximity variables are necessarily collinear with the number of riots and the time-decay diffusion indicators. Furthermore, each of the proposed network structures reflects clusters of cities that are geographically concentrated. To be certain that the media network effects are not merely distance-in-disguise, geographic distance must be controlled. Furthermore, because the set of network ties in the asymmetric network is a subset of the ties in the responsive network, it 
TABLE 4

The Effects of Short-Term Network Proximity Using Additional Controls

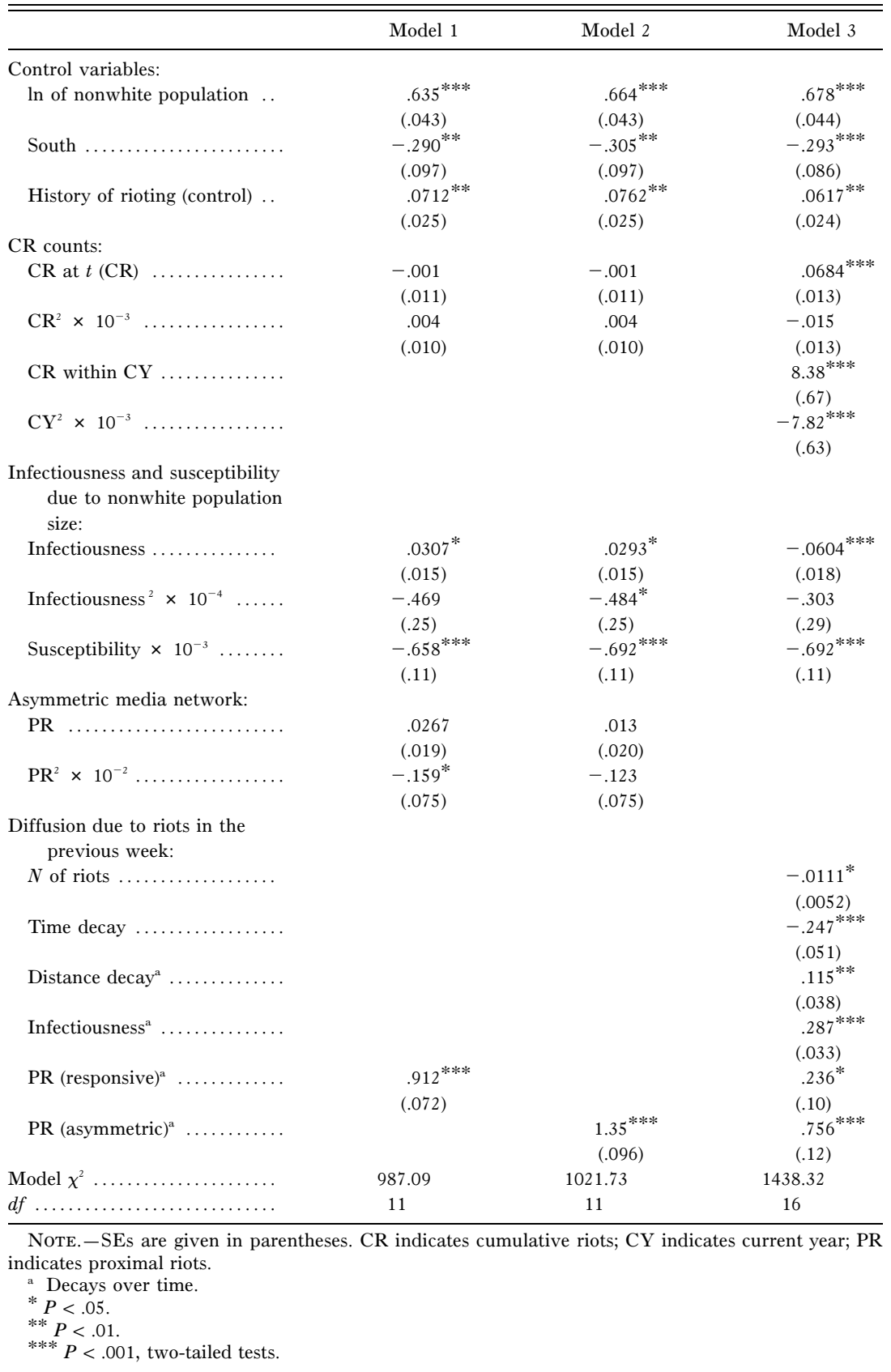




\section{Collective Violence}

is not clear whether the effect of riots in the responsive network is due only to the effects in the asymmetric network.

The final model given in table 4 answers these questions. This model includes both network proximity variables plus all the variables used in model 1 of table $2 .{ }^{23}$ In this model, both riot proximity variables remain significant although the effect due to riots in the responsive network is substantially attenuated. While both proximity variables contribute significantly to model fit, the asymmetric operationalization of media network structure accounts for most of the effect. In other words, any riot that breaks out in a television station's distribution radius increases the likelihood of more rioting within that radius, but riots that break out in cities that have television stations are substantially more contagious.

\section{DISCUSSION}

Since the 1960s, the empirical question of why collective violence breaks out where and when it does has dominated the study of riots. Despite the large amount of effort invested in answering these questions, surprisingly little progress has been made. Perhaps one reason why so little has been gained from so much effort is that analysts typically have treated riot events as independent from one another and collective actors as independent from one another, when they are not. As information about the behavior of one collective event is broadcast to other individuals, they react. These reactions may increase (by spurring imitation) or decrease (by spurring repression) future collective acts of the same nature. Without understanding how influence is transmitted, flows, and is received through communication networks, we cannot achieve a thorough understanding of collective violence and protest waves.

The results presented in this article take a step forward in this agenda by examining several important questions about influence in diffusion processes. The first question examined in the article addresses whether events differ in how contagious they may be. In other words, did extremely intense riots such as Watts, Newark, and Detroit result in more imitation than did small civil disorders in which no one was killed or injured, few were arrested, and little property damage was done? The results show that indeed severe riots were considerably more influential than smaller ones. This effect, however, is relatively short-lived. Each day, the contagious effect of a riot dissipates until about one week has passed, at which time it no longer has much of an effect on rioting.

The second question examined in the article is whether or not some

${ }^{23}$ The long-term network proximity indicators $\left(\mathrm{PR}\right.$ and $\left.\mathrm{PR}^{2}\right)$ were eliminated from this model given their ineffectiveness in models 1 and 2 . 


\section{American Journal of Sociology}

collective actors are more likely than others to imitate. As many diffusion and network theorists have pointed out, connected actors in a social system do not all have the same influence on each other and are not all influenced the same way. These differences may stem from a number of sources including characteristics of the actors that do not necessarily make them more likely to act on their own but make them more likely to imitate the actions of others. The results show that this factor does come into play among cities in the riot wave. Cities with small black populations are far more likely to imitate larger cities than the other way around. Of course, cities with larger black populations are more likely to riot in the first place, so the susceptibility factor has the effect of reducing the gap between the riot rates of small and big cities over the long term. In other words, there are always substantially more riots in big cities than in small ones, but this difference wanes over time because riots in the big cities are propelling additional riots in small cities, but the riots in small cities are being ignored by the big cities.

The third major set of results in the article demonstrates how influence flows through a communication network that connects cities. Network diffusion influence does not flow continuously throughout the action wave, however. Instead, we find that influence from riots flows through the communication web only for short periods of time.

The combination of these results underscores two broad points about the diffusion of collective violence and the diffusion of social behaviors in general. First, the influence of diffusion on producing collective behavior is immense. Over the past 30 years, the dominant model for predicting rioting has been the one introduced by Spilerman in 1970 when he claimed that little else matters in predicting riots other than the size of the black population in a city and whether or not it was located in the South. Studies that followed produced only small increments in predictive power over Spilerman's simple formulation. Furthermore, some of these gains were achieved in part by neglecting one or both of Spilerman's key variables, leading to the conclusion that these results are statistical artifacts rather than meaningful processes. The same cannot be said of the diffusion effects presented in this study. If one compares a model representing Spilerman's favored formulation to model 3 of table $4,{ }^{24}$ the difference is more than significant and suggests that analyses of rioting that fail to incorporate diffusion notions are seriously misspecified. Diffusion, therefore, was a fundamental determinant of the rioting in this collective action sequence, and if these results are at all portentous, diffusion will

\footnotetext{
${ }^{24}$ For example, a restricted version of model 1 of table 1, using only the three "control" variables, produces coefficients roughly equivalent to those presented in table 1 and the model $\chi^{2}=464.22, d f=3$.
} 


\section{Collective Violence}

be found to be an extraordinarily important force in other waves of collective violence and other social protests as well.

The second broad observation drawn from these results is the extraordinary importance of the mass media in driving waves of collective behavior. The diffusion of a social process depends on communication networks. If potential adopters never receive information about others' previous behavior, they can never evaluate its outcomes or imitate it. Access to the communication network, therefore, is a critical prerequisite to the diffusion of collective behavior, and the mass media is the key communication network that drives all three of the major findings. The infectiousness of a riot is a function of its severity, but the reason this effect exists is because severity is linked to future rioting by the mass media. Gatekeepers who control the mass media judge events according to their newsworthiness, and those events that are not newsworthy enough are not broadcast in print or over the airwaves. Riots mainly increase in newsworthiness with increases in property damage, injuries, deaths, and repression.

Differences in susceptibility also appear to be heavily influenced by the media. In the present empirical case, susceptibility seems to be an indicator of long-standing patterns of communication flow rather than a function of specific incidents (as was the case for infectiousness). Instead, susceptibility reflects the relative cultural and political importance of larger populations. The selectivity of mass media gatekeepers is affected by the differences in importance among the audiences it serves such that there is a differential neglect of events in peripheral areas compared to those in the core. This neglect allows events in large core cities to be more influential than events from smaller outlying areas.

More evidence for this core-periphery bias is found when the television broadcast networks among cities are mapped. Beyond the results showing the general impact of mass media (riots are more contagious within the broadcast area of a television station), they also demonstrate that cities with television stations have considerably more impact on cities without television stations than the other way around. This effect may result from a process similar to that which seems to be driving differences in susceptibility. That is, media gatekeepers could be judging that events in the core are more newsworthy than those in the periphery. A second possibility, however, is that a difference in media resources is driving the pattern. That is, core cities have the resources (television stations) to broadcast their influence (in this case, news about their own riots), while peripheral cities do not. Whether either process or both are functioning, the result is a further exaggeration of the influence of riots in large, media-rich cities.

In addition to the significant diffusion factors located, the lack of support for some hypotheses is also noteworthy. For example, infectiousness 
American Journal of Sociology

and network indicators were found to be ineffective predictors of longterm trends in riot rates. Findings like these emphasize that each diffusing phenomenon must be carefully examined in order to understand how the influence processes work. Unlike diffusing innovations, which exert a constant influence once they are adopted, the influence of rioting starts with an immediate spike that is accentuated by the severity of a riot and then quickly declines. One reason riots have such a time-limited influence is that they themselves do not last very long. In contrast, a diffusing technology (such as tractors or color television) continues to be used by the same actor after adoption and therefore can continue exerting influence on others to adopt. Second, riots are dependent on the mass media to carry their contagious influence, and media attention can be very shortlived. Once a riot is over, the media will cease to present it to the public, and it will lose its potential to forward the diffusion process.

The diffusion of a social phenomenon is a complex process made up of a large number of subprocesses. While event history diffusion modeling has provided a new means for specifying and investigating these processes, the approach is still relatively young, and there remains a great deal of terrain to map. Because of this, the current analysis is far from a comprehensive statement on diffusion processes in collective violence. For example, the operationalization of infectiousness, susceptibility, and influence networks used herein does not exhaust the possibilities. Other indicators of prestige or prominence among the set of actors, for example, might index infectiousness or susceptibility. Furthermore, the negative effect of infectiousness in the latter portion of the riot cycle suggests the possibility of negative diffusion effects. These may be thought of as inoculation effects tied to the time since the last event or the total number of events in a city. The inoculation effect could provide temporary or permanent resistance to contagious influence. Other characteristics of cities, like the structural and economic factors used in earlier riot studies, may be useful as susceptibility indicators because they indicate fertile ground for an ideology that supports rioting as a protest tactic. Finally, there is the question of the effect of repression on diffusion. On one hand, repression is keyed to the severity of a riot, and repressive force may actually increase the severity of a riot. On the other, repression should decrease the positive reinforcements for rioting and thereby curtail diffusion. Exactly how different kinds and scales of repression affect diffusion of collective violence remains an open question.

Questions also remain regarding the microprocesses that drive the diffusion of collective violence. Given these results, it is difficult to deny that diffusion is operating, but details of the communication transmission process are still not well understood. For example, it is not completely clear why the psychological effects of prior riots are so short-lived. Oliver (1989) 


\section{Collective Violence}

says it may be because people have had a chance to decide and act. But there is not, as yet, reason to believe that the decision-making process occurs in any particular time-frame. Furthermore, once potential rioters make the decision to support rioting behaviorally, they do not necessarily immediately head out into the streets. Instead there must be a spark, a precipitating incident, that sets off rioting and provides an opportunity for adherents to put their conviction into action. Increased acceptance of an action plan certainly increases the probability that precipitating incidents will arise and the reaction to the precipitating incident will be a riot. Often these opportunities are not ubiquitous, however, and therefore the action supporting the decision will be delayed. What happens to the convictions of those who made the decision to support rioting while they are waiting? What is the psychological effect of additional riots that happen during the waiting period?

Finally, details of the media selection process remain. I have suggested one plausible model, which involves media responsiveness to its core audience, but I have not in any detailed sense demonstrated the validity of this process model. What are the processes of reasoning news editors use to determine who is the core audience, what is important to that audience, and how much they will cater to that audience? It seems clear that larger cities with television stations act as opinion leaders in some way, but details of this arrangement and its limitations remain unclear. Ongoing work toward understanding reporting patterns for collective events (e.g., McCarthy, McPhail, and Smith 1996; McCarthy et al. 1998; Mueller 1997; Oliver and Maney 1998; Oliver and Myers 1999) continues to contribute to this agenda, but in some sense, the work has only just begun.

\section{APPENDIX}

\section{Computation of Riot Severity Index}

Five indicators of riot severity, (1) the number of arrests, (2) the number injured, (3) the number of arsons, (4) the number killed, and (5) the number of days of rioting, were combined to produce a composite severity index. Intuitively, crowd size is the most obvious indicator of riot intensity, but it is not employed here because of the high level of missing data and the notorious inaccuracy of crowd estimates. Property damage is another obvious indicator of severity, but it is also difficult to obtain for most riots. Therefore, the number of arsons is used as a proxy for property damage. (See Carter [1983] for detailed evidence justifying this proxy.) 
American Journal of Sociology

TABLE A1

FACtor ANAlysis Results for SEverity Indicators

\begin{tabular}{lcc}
\hline \hline & Factor Loading & Factor Scores \\
\hline$N$ injured $\ldots \ldots$. & .714 & .233 \\
$N$ arrested $\ldots \ldots$. & .786 & .311 \\
$N$ killed $\ldots \ldots \ldots$ & .571 & .122 \\
Riot duration $\ldots$. & .689 & .177 \\
$N$ arsons $\ldots \ldots \ldots$ & .777 & .317 \\
\hline
\end{tabular}

TABLE A2

CORRELATION MATRIX FOR SEVERITy INDICATORS

\begin{tabular}{lcccccc}
\hline \hline & Arrested & Arson & Duration & Injured & Killed & Severity \\
\hline Arrested ... & $\ldots$ & & & & & \\
Arson ..... & .582 & & & & & \\
Duration ... & .549 & .621 & & & & \\
Injured ..... & .610 & .476 & .458 & & & \\
Killed ...... & .417 & .479 & .307 & .487 & & \\
Severity .... & .861 & .834 & .704 & .768 & .556 & $\ldots$ \\
\hline
\end{tabular}

To combine the five severity indicators, I closely followed the method used by Carter (1983, 1986). Because the current analysis is focused on the event-level, however, I calculated severity for each individual riot rather than aggregating across all riots within a single city, as he did. For each indicator of severity, the raw numbers were log-transformed $(\ln [\mathrm{raw}+1]$, except the duration in days: $\ln [\mathrm{raw}])$. Using these values, the data were subjected to a principle axis factor analysis with iterations. Only one factor was identified, and all severity indicators loaded strongly on this factor (see table A1). Using the factor scores produced by the factor analysis, the log-transformed raw scores for each set of severity indicators were weighted by the appropriate factor score and summed across the five indicators to produce the severity index. This index is highly correlated with each of the individual severity indicators (mean correlation $=$ .745; see table A2) and surpasses each as an indicator of severity by incorporating information from all of the other indicators. Furthermore, this method has been shown to produce severity scores highly correlated with previously developed severity indicators (see Carter [1983] for details).

\section{REFERENCES}

Aguirre, B. E., E. L. Quarantelli, and Jorge L. Mendoza. 1988. "The Collective Behavior of Fads: The Characteristics, Effects, and Career of Streaking." American Sociological Review 53:569-84. 


\section{Collective Violence}

Allison, Paul D. 1984. Event History Analysis: Regression for Longitudinal Event Data. Newbury Park, Calif.: Sage Publications.

Bobo, Lawrence. 1988. "Attitudes toward the Black Political Movement: Trends, Meaning, and Effects on Racial Policy Preferences.” Social Psychology Quarterly 51:287-302.

Bohstedt, John. 1994. "The Dynamics of Riots: Escalation and Diffusion/Contagion." Pp. 257-306 in The Dynamics of Aggression, edited by Michael Potegal and John Knutson. Hillsdale, N.J.: Lawrence Erlbaum Associates.

Bohstedt, John, and Dale Williams. 1988. "The Diffusion of Riots: The Patterns of 1766, 1795, and 1801 in Devonshire." Journal of Interdisciplinary History 19:1-24.

Burt, Ronald S. 1987. "Social Contagion and Innovation: Cohesion versus Structural Equivalence." American Journal of Sociology 2:1287-335.

Button, James, W. 1978. Black Violence. Princeton, N.J.: Princeton University Press.

Carter, Gregg Lee. 1983. Explaining the Severity of the 1960's Black Rioting. Unpublished dissertation. Columbia University, Department of Sociology.

— 1986. "The 1960s Black Riots Revisited: City Level Explanations of Their Severity." Sociological Inquiry 56:210-28.

Charlesworth, Andrew. 1979. Social Protest in a Rural Society. Cambridge: Institute of British Geographers.

Coleman, James S., Eliho Katz, and Herbert Menzel. 1966. Medical Innovation. Indianapolis: Bobbs-Merrill.

Cox, D. R. 1972. "Regression Models and Life Tables." Journal of the Royal Statistical Society, series B, 34:187-202.

Crump, Spencer. 1966. Black Riot in Los Angeles: The Story of the Watts Tragedy. Los Angeles: Trans-Anglo Books.

Danzger, Herbert M. 1975. "Validating Conflict Data." American Sociological Review 40:570-84.

Davis, Gerald F., and Henrich R. Greve. 1997. "Corporate Elite Networks and Governance Changes in the 1980s." American Journal of Sociology 103:1-37.

Feagin, Joe R., and Harlan Hahn. 1973. Ghetto Revolts: The Politics of Violence in American Cities. New York: MacMillan.

Fogelson, Robert M. 1969. "White on Blacks: A Critique of the McCone Commission Report on the Los Angeles Riots." Pp. 113-43 in The Los Angeles Riots, edited by R. M. Fogelson. New York: Arno.

Franzosi, Roberto. 1987. "The Press as a Source of Socio-Historic Data: Issues in the Methodology of Data Collection from Newspapers." Historical Methods 20:5-15.

Freud, Sigmund. 1921. Group Psychology and Analysis of Ego. London: International Psychoanalytic Press.

Gans, Hebert. 1980. Deciding What's News: A Study of CBS Evening News, NBC Nightly News, Newsweek, and Time. New York: Vintage.

Governor's Commission on the Los Angeles Riots. 1965. Violence in the City-an End or a Beginning? Los Angeles: State of California.

Greve, Henrich R., David Strang, and Nancy Brandon Tuma. 1995. "Specification and Estimation of Heterogeneous Diffusion Models." Sociological Methodology 25: $377-420$.

Hacker, Frederick J., and Aljean Harmetz. 1969. "The Riot: A Liberating, Identifying Force." Pp. 87-92 in Urban Racial Violence in the Twentieth Century, edited by Joseph Boskin. Beverly Hills, Calif.: Glencoe Press.

Hamblin, Robert L., R. Brooke Jacobsen, and Jerry L. L. Miller. 1973. A Mathematical Theory of Social Change. New York: John Wiley \& Sons.

Hedström, Peter. 1994. "Contagious Collectivities: On the Spatial Diffusion of Swedish Trade Unions, 1890-1940.” American Journal of Sociology 99:1157-79.

Herman, Edward, and Noam Chomsky. 1988. Manufacturing Consent. New York: Pantheon. 


\section{American Journal of Sociology}

Hobsbawn, Eric J., and George Rudé. 1968. Captain Swing. New York: Norton.

Issac, Larry, and William R. Kelly. 1981. "Racial Insurgency, the State, and Welfare Expansion: Local and National Evidence from the Post-war United States." American Journal of Sociology 86:1348-86.

Jiobu, Robert M. 1971. "City Characteristics and Racial Violence." Social Science Quarterly 55:52-64.

Knoke, David, and James H. Kuklinski. 1982. Network Analysis. Newbury Park, Calif.: Sage.

Land, Kenneth C., and Glenn Deane. 1992. "On the Large-Sample Estimation of Regression Models with Spatial- or Network-Effects Terms: A Two-Stage Least Squares Approach.” Sociological Methodology 22:221-48.

Land, Kenneth C., Glenn Deane, and Judith R. Blau. 1991. "Religious Pluralism and Church Membership: A Spatial Diffusion Model." American Sociological Review $56: 237-49$.

LeBon, Gustave. [1895] 1960. The Crowd: A Study of the Popular Mind. New York: Viking Press.

Lieske, Joel A. 1978. "The Conditions of Racial Violence in American Cities: A Developmental Synthesis." American Political Science Review 72:1324-40.

Lipsky, Micheal. 1968. "Protest as a Political Resource." American Political Science Review 62:1144-58.

Mahajan, Vijay, and Robert A Peterson. 1985. Models for Innovation Diffusion. Beverly Hills, Calif.: Sage Publications.

Marsden, Peter V., and Joel Podolny. 1990. "Dynamic Analysis of Network Diffusion Processes." Pp. 197-214 in Social Networks through Time, edited by Henk Flap and Jeroen Weesie. Utrect: ISOR.

Marx, Gary T. 1967. Protest and Prejudice: A Study of Beliefs in the Black Community. New York: Harper \& Row.

McAdam, Doug. 1982. Political Process and the Development of Black Insurgency, 1930-1970. Chicago: University of Chicago Press.

. 1983. "Tactical Innovation and the Pace of Insurgency." American Sociological Review 48:735-54.

McCarthy, John D., Clark McPhail, and Jackie Smith. 1996. "Images of Protest: Dimensions of Selection Bias in Media Coverage of Washington Demonstrations." American Sociological Review 61:478-99.

McCarthy, John D., Larissa Titarenko, Clark McPhail, and BoguslawAugustyn. 1998. "Media Source and Temporal Stability in Selection Bias of Newspaper Coverage of Protest Events: A Comparison of Four Daily Newspapers through Stages of a Transition from Communism in Minsk, Belarus.” Paper presented at the 1998 Annual Meeting of the American Sociological Association, San Francisco.

McPhail, Clark. 1991. The Myth of the Madding Crowd. New York: DeGruyter. . 1994. "Presidential Address-The Dark Side of Purpose: Individual and Collective Violence in Riots." Sociological Quarterly 35:1-32.

Morenoff, Jeffrey D., and Robert J. Sampson. 1997. "Violent Crime and the Spatial Dynamics of Neighborhood Transition: Chicago, 1970-1990." Social Forces 76: 31-64.

Morgan, William R., and Terry Nichols Clark. 1973. "The Causes of Racial Disorders: A Grievance-Level Explanation.” American Sociological Review 38:611-24.

Mueller, Carol. 1997. "International Press Coverage of East German Protest Events, 1989." American Sociological Review 62:820-32.

Myers, Daniel J. 1996. "The Diffusion of Collective Violence." Paper presented at the 1996 Annual Meeting of the American Sociological Association, New York.

1997a. Diffusion Models for Riots and Other Collective Violence. Ph.D. dissertation. University of Wisconsin, Department of Sociology. 


\section{Collective Violence}

1997b. "Racial Rioting in the 1960s: An Event History Analysis of Local Conditions." American Sociological Review 62:94-112.

Myers, Daniel J., and Beth Schaefer Caniglia. 2000. "Media Bias in the Coverage of Racial Riots: National versus Local Media Outlets." Paper presented at the 2000 Annual Meeting of the Midwest Sociological Society, Chicago.

National Advisory Commission on Civil Disorders. 1968. Report of the National Advisory Commission on Civil Disorders. New York: Bantam Books.

Newton, Huey P. 1973. Revolutionary Suicide. New York: Harcourt Brace Jovanovich.

Oberschall, Anthony. 1980. "Loosely Structured Collective Conflict." Research in Social Movements, Conflict and Change 3:45-68.

. 1989. "The 1960 Sit-ins: Protest Diffusion and Movement Take-off." Research in Social Movements, Conflict and Change 11:31-53.

Oliver, Pamela E. 1989. "Bringing the Crowd Back In: The Nonorganizational Elements of Social Movements." Research in Social Movements, Conflict and Change 11:1-30.

Oliver, Pamela E., and Gregory M. Maney. 1998. "Making the Local News: Police and Media Records of Protest Events in a Small Town." Paper presented at the 1998 Annual Meeting of the American Sociological Association, San Francisco.

Oliver, Pamela E., and Daniel J. Myers. 1999. "How Events Enter the Public Sphere: Conflict, Location and Sponsorship in Local Newspaper Coverage of Public Events." American Journal of Sociology 105 (1): 38-87.

Olzak, Susan. 1987. "Causes of Ethnic Protest and Conflict in Urban America, 1877-1889." Social Science Research 16:185-210.

1992. The Dynamics of Ethnic Competition and Conflict. Stanford, Calif.: Stanford University Press.

Olzak, Susan, and Suzanne Shanahan. 1996. "Deprivation Race Riots: An Extension of Spilerman's Analysis.” Social Forces 74:931-61.

Olzak, Susan, Suzanne Shanahan, and Elizabeth H. McEneaney. 1996. "Poverty, Segregation, and Race Riots: 1960 to 1993." American Sociological Review 61: 590-613.

Paige, Jeffery. 1975. Agrarian Revolution. New York: Free Press.

Pitcher, Brian L., Robert L. Hamblin, and Jerry L. L. Miller. 1978. "Diffusion of Collective Violence." American Sociological Review 43:23-35.

Rogers, Everett M. 1995. Diffusion of Innovations, 4th ed. New York: Free Press.

Sears, David G., and T. M. Tomlinson. 1968. "Riot Ideology in Los Angeles: A Study of Negro Attitudes.” Social Science Quarterly 49:485-503.

Shanahan, Suzanne, and Susan Olzak. 1998. "Collective Conflict in the United States, 1869-1924: Understanding the Impact of Diversity upon American Race Relations." Paper presented at the 1998 Annual Meeting of the American Sociological Association, San Francisco.

Snyder, David, and William R. Kelly. 1977. "Conflict Intensity, Media Sensitivity and the Validity of Newspaper Data." American Sociological Review 42:105-23.

Soule, Sarah A. 1997. "The Student Divestment Movement in the United States and Tactical Diffusion: The Shantytown Protest." Social Forces 75:855-82.

Soule, Sarah A., and Yvonne Zylan. 1997. "Runaway Train? The Diffusion of StateLevel Reform in ADC/AFDC Eligibility Requirements, 1950-1967." American Journal of Sociology 103:733-62.

Spilerman, Seymour. 1970. "The Causes of Racial Disturbances: A Comparison of Alternative Explanations.” American Sociological Review 35:627-49

. 1971. "The Causes of Racial Disturbances: Test of an Explanation." American Sociological Review 36:427-42.

- 1976. "Structural Characteristics of Cities and the Severity of Racial Disorders." American Sociological Review 41:771-93.

Stark, Margaret J. Abudu, Walter J. Raine, Stephen L. Burbeck, and Keith K. Davison. 


\section{American Journal of Sociology}

1974. "Some Empirical Patterns in a Riot Process." American Sociological Review 39:865-76.

Strang, David. 1990. "From Dependency to Sovereignty: An Event History Analysis of Decolonization 1870-1987." American Sociological Review 55:846-60.

. 1991. "Global Patterns of Decolonization, 1500-1987." International Studies Quarterly 35:429-54.

. 1995. Mhdiff: User Documentation. Technical Report 95-3. Cornell University, Department of Sociology.

Strang, David, and Sarah A. Soule. 1998. "Diffusion in Organizations and Social Movements: From Hybrid Corn to Poison Pills." Annual Review of Sociology 24: 265-90.

Strang, David, and Nancy Brandon Tuma. 1993. "Spatial and Temporal Heterogeneity in Diffusion." American Journal of Sociology 99:614-39.

Television Digest, Inc. 1968. Television Factbook: 1968-1969, no. 38. Washington, D. C.: Televison Digest, Inc.

Tilly, Charles. 1969. "Methods for the Study of Collective Violence." Pp. 15-43 in Problems in Research on Community Violence, edited by R. Conant and M. A. Levin. New York: Praeger.

Tolnay, Stewart E. 1995. "The Spatial Diffusion of Fertility: A Cross-Sectional Analysis of Counties in the American South, 1940." American Sociological Review 60:299-308.

Tolnay, Stewart E., Glenn Deane, and E. M. Beck. 1996. "Vicarious Violence: Spatial Effects on Southern Lynchings, 1890-1919.” American Journal of Sociology 102: $788-815$.

Tomlinson, T. M. 1968. "The Development of a Riot Ideology among Urban Negroes." American Behavioral Scientist 2:27-31.

Useem, Bert. 1998. "Breakdown Theories of Collective Action." Annual Review of Sociology 24: 215-38.

Valente, Thomas W. 1995. Network Models of the Diffusion of Innovations. Cresskill, N.J.: Hampton Press.

Waddington, David. 1992. Contemporary Issues in Public Disorder: A Comparative and Historical Approach. London: Routledge. 